Research paper

\title{
Analysis of traditional preparation methods of buckwheat noodles in Japan
}

\section{Yuya ASAMI ${ }^{1}$, Yoshinobu YAMASHITA ${ }^{2}$, Takahiro OKA ${ }^{2}$, Takanori TERAO $^{3}$, Satoshi ITO $^{2}$, Sayoko IKEDA ${ }^{2}$, Ayumi NISHIHANA ${ }^{2}$, Natsumi MITSUMATA ${ }^{2}$ and Kiyokazu IKEDA*2}

1 Department of Food Science and Human Nutrition, Faculty of Agriculture, Ryukoku University, Otsu 520-2194, Japan

2 Faculty of Nutrition, Kobe Gakuin University,

Nishi-ku, Kobe 651-2180, Japan

3 Terao Milling Company, Himeji, Hyogo, Japan

* Corresponding author:

Prof. Kiyokazu Ikeda

Faculty of Nutrition, Kobe Gakuin University, Nishi-ku Kobe 651-2180, Japan

Fax +81789745689

DOI https://doi.org/10.3986/fag0003

Received September 30, 2017; accepted October 1, 2017

Keywords:

common buckwheat, mechanical characteristics, noodles,

traditional buckwheat noodle method

\section{ABSTRACT}

The present study was undertaken to clarify two subjects, i.e., one subject is to clarify the mechanical characteristics on the kukuri (kneading) and kiku-neri (forming into a chrysanthemum flower-like shape) processes on the preparation of buckwheat noodles; and another problem, to compare mechanical characteristics with buckwheat flours with different particle size. The present study shows some factors which lie behind traditional methods preparing buckwheat noodles, i.e., some factors behind the kukuri and kiku-neri processes. Furthermore, this present study shows that the particle size of buckwheat flour may be an important factor affecting the mechanical characteristics of buckwheat noodles. 


\section{INTRODUCTION}

Buckwheat (Fagopyrum esculentum Moench) is an important crop in many countries of the world (Ikeda, 2002; Kreft et al., 2003). Buckwheat flour is processed into various products such as noodles, pasta etc. There is a large variety of buckwheat products globally. In view of their processing, increasing attention has been paid to clarifying scientific basis for the palatability and acceptability of various buckwheat products.

Noodles made from buckwheat flour-water dough are popular in some regions including Japan (Ikeda, 2002). In Japan, buckwheat noodles are a popular, traditional food. Traditional methods preparing buckwheat noodles have been cultivated in the Japan for about four hundred years or over (Zen-men-kyo, 2014; Asami et al., 2016). The traditional methods preparing buckwheat noodles generally consist of six successive processes. The first process is mixing buckwheat flour by hand in a wooden bowl with water in the presence of some additives such as wheat flour to make dough. This process is called mizumawashi which means mixing buckwheat flour with water. The second process is kneading buckwheat dough and foaming it

Mechanical characteristics on human mastication may be important on various foods, especially buckwheat noodles. On into a circle form. This process is called kukuri which means kneading and forming. The third process; is binding the dough into a chrysanthemum flower-like shape (Fig. 1). This process is called kiku-neri: Kiku means chrysanthemum flower; and neri, binding. It is generally thought that both the kukuri and kiku-neri processes may be the most important ones in the preparation of buckwheat noodles. In addition, the fourth process is extending the ball-shaped dough into a thin, rectangular shape using a long wooden-bar. This process is called nobashi which means expanding. The fifth process is softly-folding the thin, rectangleshaped dough. This process is called tatami which means folding. The last process is cutting the folded dough using a big knife to prepare long resultant buckwheat noodles. This process is called houchou which means cutting with the knife. In general, buckwheat noodles with high palatability are prepared by the traditional method in Japan. Many Japanese people enjoy palatable buckwheat noodles. It appears that scientifically-excellent techniques may lie behind each process of such traditional methods. In viewpoint of food science, there are various questions concerning traditional methods for buckwheat noodles.

the other hand, there are various kinds of buckwheat flour with different particle size of the flour. Such different buckwheat flours 
are widely utilized for the preparation of various buckwheat noodles in Japan. It is also interesting to clarify what mechanical sense on human mastication may be arisen with each of various, different buckwheat flours, respectively. We have recently undertaken a series of studies to clarify the scientific basis responsible for traditional processing techniques for buckwheat noodles with special regards to mechanical analyses (Ikeda et al., 1997; Ikeda et al., 1999; Asami et al., 2008; Asami et al., 2009; Asami et al., 2010; Asami et al., 2012; and Asami et al., 2016). However, there are still many, unanswered questions for traditional, excellent techniques in the preparation of buckwheat noodles.

\section{MATERIALS AND METHODS}

\section{Materials}

Buckwheat flour (Fagopyrum esculentum Moench, var. Kitawase-soba), which was harvested in Hokkaido (in 2016), was used in this research. Different buckwheat flours with different particle sizes and wheat medium flour were kindly provided prepared by Terao Milling Co. (Hyogo, Japan) and stored at $-80^{\circ} \mathrm{C}$ until use.

\section{Preparation of buckwheat noodles}

Buckwheat noodles were hand-made by $Y$. Yamashita and T. Oka, who are the present authors, and buckwheat noodlepreparation experts. Y. Yamashita has the fifth grade, the highest grade, of preparing buckwheat noodles, which was awarded by
Especially, the scientific reason for the ukuri and kinu-neri processes is the subject of much interest. In addition, comparison study on analysis of noodle preparing methods using various buckwheat flour with different particle sizes is also an interesting subject. The present study was undertaken to clarify two subjects, i.e., one subject is to clarify mechanical characteristics of the kukuri (kneading) and kiku-neri (forming buckwheat noodles into a chrysanthemum flower-like shape) processes on the preparation of buckwheat noodles; and another problem, to compare mechanical characteristics with various, different buckwheat flours.

the Japan Buckwheat Noodles Association (Zen-men-kyo). T. Oka has the fourth grade awarded by the Zen-men-kyo. Buckwheat noodles were prepared by $\mathrm{Y}$. Yamashita and T. Oka according to the traditional method described previously (Zen-men-kyo, 2014). Two experiments, I and II, were conducted in the present study. Experiment I was performed to analyze the mechanical role of kiku-neri process of preparing buckwheat noodles, i.e., mechanical characteristics of buckwheat noodles prepared under three different conditions in the kiku-neri process were compared. Experiment II was performed to compare mechanical characteristics of three buckwheat noodles prepared with three different types of flour particle size. 


\section{Mechanical measurements}

Before mechanical measurements, prepared buckwheat noodles were cooked in boiling water for $40 \mathrm{sec}$ and were subsequently cooled for $40 \mathrm{sec}$ at $4^{\circ} \mathrm{C}$ Immediately after cooling, mechanical measurements of the noodles were performed. Breaking characteristics of buckwheat noodles were evaluated using a Rheoner RE2-3305C (Yamaden Co. Ltd., Japan). Measurements of breaking analysis were performed with a load cell of $2000 \mathrm{~N}$ and a measurement speed of 0.50 $\mathrm{mm} / \mathrm{sec}$. A wedge-style plunger (No.49: W $13 \mathrm{~mm}$, D $30 \mathrm{~mm}, \mathrm{H} 25 \mathrm{~mm}$ ) was used in measurements with the Rheoner RE-3305.

\section{Measurements of water absorption}

Measurements of maximum water absorption capacity (MaxWAC) of buckwheat flours in experiment II were assayed using the method of Hashimoto (1991).
Mechanical measurements of the buckwheat noodles were repeated twenty times for each sample.

\section{Measurements of particle size}

Measurements of the particle size of buckwheat flours in experiment II were performed by Shimadzu Techno-Research, Inc., Japan. Measurements of the particle size were performed using a SALD-2300 (Shimadzu, Japan). The easurements were performed with a cyclonic type dry measuring unit DS5, a dispersion pressure of $0.4 \mathrm{MPa}$, a table lifting speed of $4 \mathrm{~mm} / \mathrm{sec}$, a refractive index using 1.50-0.01i.

\section{Statistical analysis}

Statistical analysis was conducted using a personal computer with the program Excel (Microsoft Co., USA) and Ekuseru-Toukei 2015 (Social Survey Research Information Co., Japan).

\section{RESULTS AND DISCUSSION}

Experiment I: Analyze the role of dough-kneading and dough-forming in to a chrysanthemum-flower shape 

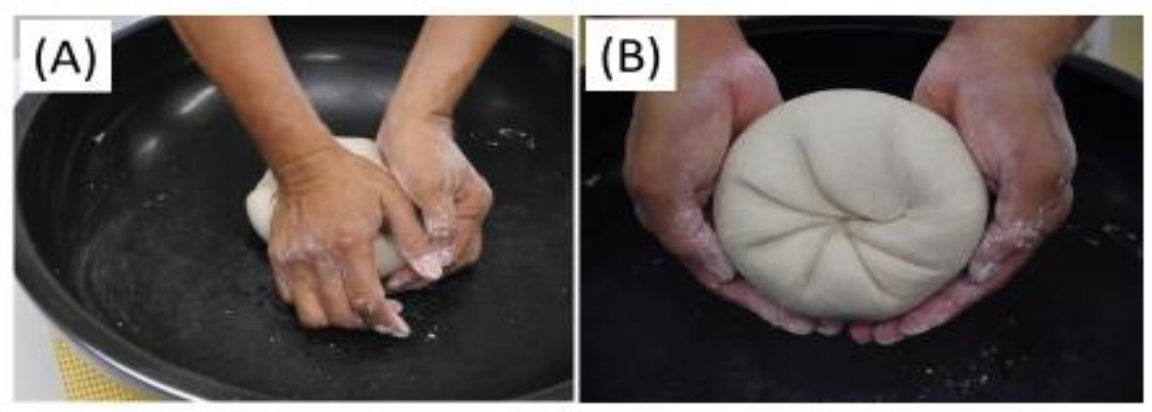

Fig. 1 Forming buckwheat dough into a chrysanthemum flour-form. This figure is cited from Asami et al., (2016) the reference in the present paper. (A, left) shows kukuri (kneading) process; (B, right), kiku-neri (forming into a chrysanthemum-flower shape) process.
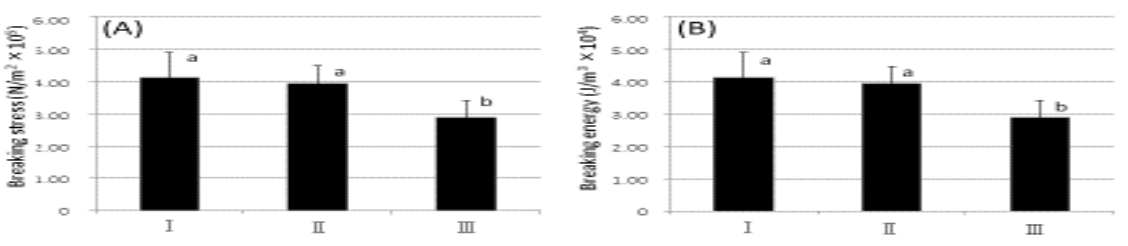

Fig. 2 Mechanical comparison of buckwheat noodles prepared by three different buckwheat noodles prepared by three different preparing methods in view both of kneading (kukuri process) and of forming a chrysanthemum flower-like dough (kiku-neri process). (A), breaking stress and (B), breaking energy. I, noodles prepared both with kneading and with forming into a chrysanthemum flower-like dough; II, noodles prepared with kneading but without forming into a chrysanthemum flower-like dough; and III, noodle prepared both without kneading and without forming into a chrysanthemum flower-like dough. Vertical bars show standard deviations. Values that within the same row that are not followed by the same letter are significantly different at $p<0.05$. 
Figure 2 shows mechanical comparison of buckwheat noodles prepared by three different buckwheat noodles prepared by three different preparing methods in view both of kneading, abbreviated as kukuri process, and of forming a chrysanthemum flower-like shape (abbr. as kiku-neri process).
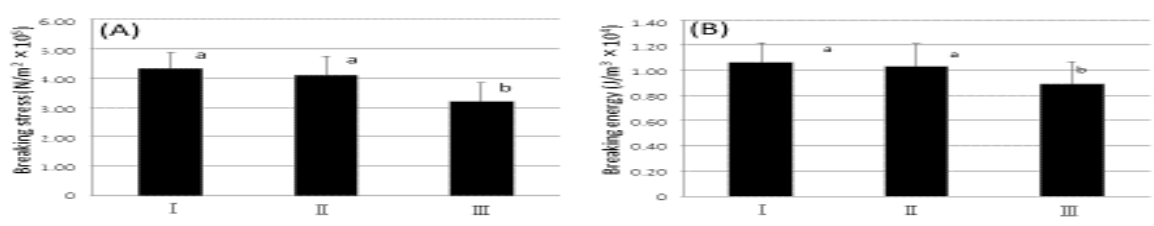

Fig. 3 Mechanical characteristics of three buckwheat noodles prepared with buckwheat flours with three different flour particle size. (A), Breaking stress and (B), Breaking energy. Noodles I was prepared with fine flour; noodles II, middle size flour; and noodles III, large flour. Vertical bars in the figure show standard deviations. Values that within the same row that are not followed by the same letter are significantly different at $\mathrm{P}<0.05$

Buckwheat noodles I were prepared both with kukuri process and with kiku-neri process; noodles II, prepared with kukuri process but without kiku-neri process; and noodles III, prepared without kukuri process and without kiku-neri process. The mechanical values of noodles III (III in Fig. $2 \mathrm{~A}$ and $\mathrm{B}$ ) was significantly lower than those of noodles I and II (I and II in Fig. 2 A and $B$ ). This finding suggests that kukuri process, i.e., kneading process may be important in mechanical characteristics in preparation of buckwheat noodles. On the other hand, there was no significant difference in the mechanical values between noodles I and II shown in I and II in Fig. $1(A)$ and $(B)(P>0.05)$. Noodles I were prepared both with kukuri process and kiku-neri process, whereas noodles II were prepared with kukuri process but without kiku-neri process. This finding shown in Fig. $2(A)$ and (B) suggests that kiku-neri process may exhibit little or substantially no effect on mechanical characteristics of buckwheat noodles. On the other hand, some cracks in buckwheat dough were often found in buckwheat dough prepared without kiku-neri process, whereas no cracks were found in buckwheat dough prepared with kiku-neri process (data not shown). Finally, the present study concludes that kiku-neri 
process, i.e., forming buckwheat dough into a chrysanthemum-like form maybe smoothly promotes subsequent procedures after kiku-neri process. Although there may be a possibility that the

\section{Experiment II: Comparison of three buckwheat noodle samples prepared} from three different particle size flours

Figure 3 shows mechanical characteristics of three buckwheat noodles prepared with buckwheat flours with three different flour particle size. Noodles I were prepared with fine flour; noodles II, middle size flour; and noodles III, large flour (Table 3). Table 1 shows the content of water (\%) added to buckwheat flour prepared, shown in Fig. 3. Table 2 shows percentage of water absorption to buckwheat noodles presented in Fig. 3 . Table 3 shows average diameter of buckwheat flour particles used in Fig. 3. The mechanical values of noodles III (III in Fig. 3A and B) was significantly lower than those of noodles I and II (I and II in Fig. 3 A and B). Relationships were analyzed on various mechanical characteristics (Fig. 3 I to III) of buckwheat flour (Tables 1 to 3 ). There was a significant positive correlation between the average diameter of buckwheat flour particles (Table 3) and maximum water absorption capacity kikuneri process may remove air from buckwheat dough which may bring about some oxidation reaction in buckwheat dough. Further research is needed.

(MaxWAC) (Table 2) of buckwheat flour ( $r=$ $0.999, \quad p<0.01)$. This is finding that buckwheat flour with larger particle size can exhibit higher MaxWAC than buckwheat flour with smaller particle size. On the other hand, there is a significant positive correlation between WAC of buckwheat flour (Table 2) and the particle size (Table 3) $(r=0.998, P<0.05)$. This finding well agrees with the above observed finding. Furthermore, a relationship of the obtained mechanical characteristics (Fig. 3) to the water addition rate at noodle preparing (Table 1) was analyzed. Interestingly, the MinWC (Table 1) correlated negatively to breaking stress with $r=-0.998(P<0.05)$, to breaking energy with $r=-0.998 \quad(p<0.05)$. These findings show that the particle size of buckwheat flour may be an important factor affecting the mechanical characteristics of buckwheat noodles. 


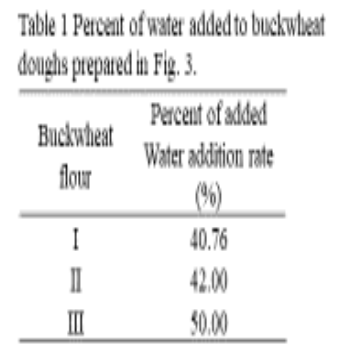

Table 2 Pencent of water absorptonto bucluderat flour usod h Fil. 3

\begin{tabular}{|c|c|}
\hline $\begin{array}{l}\text { Bucdrulkat } \\
\text { flout }\end{array}$ & $\begin{array}{l}\text { Witer absorption rate } \\
\qquad(\mathrm{g})^{*}\end{array}$ \\
\hline I & $139.2 \pm 2.8$ \\
\hline I & $143.2 \pm 1.4$ \\
\hline III & $1929 \pm 9.4$ \\
\hline \multicolumn{2}{|c|}{ 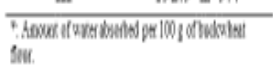 } \\
\hline \multicolumn{2}{|c|}{ 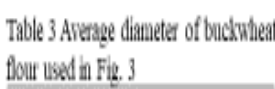 } \\
\hline $\begin{array}{l}\text { Buchwheat } \\
\text { Alous }\end{array}$ & $\begin{array}{l}\text { Arrage desantert of } \\
\text { flow (uIII) }\end{array}$ \\
\hline 1 & $108.9 \pm 0.4$ \\
\hline II & $160.6 \pm 0.4$ \\
\hline III & $687.3 \pm 0.1$ \\
\hline
\end{tabular}

Finally, the present study shows some factors which lie behind traditional methods preparing buckwheat noodles, i.e., some factors behind the kukuri (kneading) process and kiku-neri (forming into a chrysanthemum flower-like shape) process. Furthermore, the present study shows that the particle size of buckwheat flour may be an important factor affecting the mechanical characteristics of buckwheat noodles.

The exact mechanisms involved in traditional preparation methods for buckwheat noodles will be an interesting subject in the future.

\section{ACKNOWLEDGMENT}

This work was supported by the Research Institute for Food and Agriculture of Ryukoku University, Japan.

\section{REFERENCES}

Asami, Y., Mochida, N., Lin, R., Campbell, C., Kuroko, Y. and Ikeda, K. 2008. Relationship of endogenous protein components to the mechanical characteristics of buckwheat doughs. Fagopyrum 25: 49-56.

Asami, Y., T. Konishi, N. Mochida, S. Ikeda and K. Ikeda. 2008. Comparison of mechanical characteristics between buckwheat noodles prepared by two different traditional techniques. Fagopyrum 25: 45-48.

Asami, Y., K. Fujimura, K. Ishii, T. Konishi, N. Mochida, S. Ikeda and K. Ikeda, 2009. Mechanical characteristics of buckwheat noodles made by traditional preparing methods. Fagopyrum 26: 77-83. 
Asami, Y., T. Konishi, N. Mochida, S. Ikeda, Y. Yamashita and K. Ikeda, 2010. Effect of buckwheat hull on the mechanical characteristics of common buckwheat dough. Fagopyrum 27: 51-54.

Asami, Y., T. Konishi, S. Ikeda and K. Ikeda, 2012. Mechanical characteristics of resultant noodles prepared by delayed cutting of buckwheat dough. Fagopyrum 29: 17-20.

Asami, Y., Yamashita, Y., Oka, T., Ito, S., Nishihana, A., Ikeda, S., Usui, J. and Ikeda, K. 2016. Mechanical analysis of traditional preparation methods of buckwheat noodles. Fagopyrum 33: 15-20.

Asami, Y., Yamashita, Y., Oka, T., Ito, S., Nishihana, A., Ikeda, S., Usui, J. and Ikeda, K. 2016. Mechanical analysis of traditional preparation methods of buckwheat noodles. Fagopyrum 33: 15-20.

Hashimoto, S. 1991. Pentosan and water absorption of wheat flour. Bulletin of Nakamura Gakuin Junior College 23: 139141.

Ikeda, K., Kishida, M., Kreft, I. and Yasumoto, K. 1997. Endogenous factors responsible for the textural characteristics of buckwheat products. J. Nutr. Sci. Vitaminol. 43: 101-111.

Ikeda, K., Fujiwara, J., Asami, Y., Arai, R., Bonafaccia, G., Kreft, I. and Yasumoto, K. 1999. Relationship of protein to the textural characteristics of buckwheat products: analysis with various buckwheat flour fractions. Fagopyrum 16: 7983.

Ikeda, K. 2002. Buckwheat: composition, chemistry and processing. In: S.L. Taylor (ed.), Advances in Food and Nutrition Research, Academic Press, Nebraska, USA, pp.395-434.Naganuma, S. 2003. Effects of granular size of rice powder on physicochemical and cooking properties. Memoirs of the Faculty of Education and Human Studies Akita University (Natural Science) 58: 29-35.

Kreft, I., K.J. Chang, Y.S. Choi and C.H. Park (eds.), 2003. Ethnobotany of Buckwheat, Jinsol Publishing Co., Seoul.

Zen-men-kyo. 2014. Kaitei Soba-Uti Kyouhon (Revision, Textbook of buckwheat noodle making). Shibata Shoten Co., Ltd, Tokyo. 